\title{
Identification and Comparison of Power and Energy Management Capabilities of Distributed Energy Resources
}

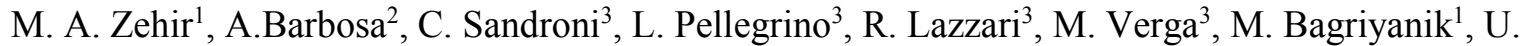 \\ Kucuk $^{4}$, F. J. Soares ${ }^{2}$, A. Ozdemir ${ }^{1}$
}

\begin{abstract}
Distributed energy resources (DERs) can provide a number of functions to be used in grid services with proper establishment of control and communication systems. However, there are neither general standards for vendor independent integration of these assets in management activities, nor common consideration of specific flexibilities that different DERs have. This paper investigates characterization and comparison of individual power and energy management flexibilities of different types of distributed energy resources. Emerging DER capability identification approaches are used to highlight contrasting differences between several energy storage and distributed generation options. Experiments were conducted in a low voltage test facility to compare flexibility limits using the same control and communication infrastructure.
\end{abstract}

Index Terms-Distributed energy resources, Energy management, Grid services, Inverter functions, Power management.

\section{INTRODUCTION}

Integration of intermittent renewables into generation system increases supply volatility and may cause several operational problems in distribution networks, while electric vehicles and similar non-stationary loads increase demand fluctuations. In addition, continuous growth of energy consumption, peak demand particularly in developing countries, considerable changes in load patterns and supply simultaneity have brought the necessity of more dependent operation on fast responding balancing resources (diesel generators, small hydro and etc.). However, they are not cost effective resources and are limited in number. Therefore, operators tend to exploit more economic alternatives and expand their asset portfolio. Advances in control and communication functions of inverters have provided management of distributed generation and storage devices as promising alternatives.

There are inspiring efforts about management of distributed energy resources (DERs) both in the literature and in the application area. A company in US provides real-time voltage monitoring service at end-user connection points to the utility operator [1]. Moreover, battery storage facilities at

${ }^{1}$ M. A. Zehir, M. Bagriyanik and A. Ozdemir are with the Dept. of Electrical Engineering, Istanbul Technical University, Istanbul, TURKEY (*corresponding author's e-mail: zehirm@itu.edu.tr).

${ }^{2}$ A. Barbosa and F. J. Soares is with the Centre for Power and Energy Systems, INESC TEC, Porto, PORTUGAL.

${ }^{3}$ C. Sandroni, L. Pellegrino, R. Lazzari and M. Verga are with Ricerca sul Sistema Energetico S.p.A., Milan, ITALY.

${ }^{4}$ U. Kucuk is R\&D Director in Makel Elektrik Malz. San. Tic. Company, Istanbul, TURKEY. customer sites can be remotely controlled by the company, to respond the events happening on the utility side. According to the results of the experimental studies proposed in [2], batteries can mitigate power and voltage fluctuations, influencing the net power supplied to the network. The researchers in [3] investigated tap changer operation performance with battery storage on a hardware-in-the-loop (PHIL) test bed. The study proposed in [4] showed that a group of PV panels can be divided into several dispatchable units using additional clustering switches (rather than being switched as a whole) and can be controlled to improve the main bus voltage profile of a microgrid. There are a number of gaps in the studies and in applications that have been conducted so far. At first, management capabilities of different DERs have not been compared with each other for the same operating conditions (use of same control and communication infrastructure). The second gap is the absence of a consensus on categorizing these devices with respect to the services that they can provide.

One of the first efforts towards defining the grid supportive functions and services can be found in a comprehensive report of Electric Power Research Institute (EPRI) [5]. It was prepared by an industry collaborative initiative with more than 500 individuals, including inverter manufacturers, system integrators, utilities, universities and research organizations. Following this effort, Electricity Markets and Policy Group from Lawrence Berkeley National Laboratory has further elaborated DER capabilities by ending up with 19 functions and 10 contexts/services [6]. The next step following these activities was defined as performing field tests to get insights and to revise the content of defined functions. These individual DER based studies can further pave the way for generalization of aggregated management options for wide deployment activities [7].

This study focuses on identification and comparison of individual power and energy management capabilities of DERs in the field. In a test facility with 9 different types of DERs (lead-acid batteries, lithium-ion batteries, vanadium redox batteries, $\mathrm{NaNiCl}$ batteries, DC grid converter, small and single phase CHP, large and three phase CHP, PV panels, small horizontal axis wind turbine) power and energy management flexibilities were characterized, using the same control and communication infrastructure. The study contributes to the growing literature on DER management area by investigating the management capability identification approaches, by pointing out common and specific capabilities of DERs and particularly by providing experimental insights from the field applications. 
Section 2 of the paper explains power and energy management flexibility identification methods adopted in this study. Section 3 provides the field experiments with results and section 4 concludes the paper.

\section{MANAGEMENT CAPABILITY IDENTIFICATION METHODOLOGY}

This section describes the methodology used for characterizing DER management flexibilities. From power and energy management point of view, six identifiers will be introduced together with the procedures for their derivation. For inverter-based resources, it is important to state that, inverter capabilities have also direct impact on the observations.

\section{A. Active/Reactive Power Supply/Demand Capability}

The maximum and the minimum active and reactive power supply/demand limits of each DER are of importance for utility-driven regulation and balancing services and also for distribution network requirements (maximum capacity relief, emergency load transfer and etc.) [8-9]. Power (and power factor for reactive power control with some inverters) set points can be increased or decreased using the control system until the device output is not changing any more. For batteries, maximum charging and discharging rates may differ, while for distributed generation, standby consumption at zero set point can be considered as demand capability. For distributed generation options from renewables, there can be significant ramps and variability (such as rapid changes in PV output in particular times of a day) in the output, requiring other controllable DERs to take action to maintain supply/demand balance.

\section{B. Maximum Storage Capacity}

Energy storage device capacities can be considered for aggregated energy related services in day-ahead and intraday wholesale markets. In addition, prosumers can take into account storage capacity to decide on storing or spending the energy generated by their local generation asset or buying energy from/selling energy to the utility. It is also important for energy management activities in islanded operation of microgrids. The amount of energy that can be stored to or supplied from a battery group mainly depends on the charging/discharging rates of the devices. Charging/ discharging with the maximum rates may reduce the useable capacity due to increasing internal resistance (consequently heat and voltage drop) of the cells causing cycles to be interrupted earlier than usual. At a lower charging/discharging rate, batteries can store/provide rather more energy. Therefore, maximum energy storage capacity can be observed in case of using the most appropriate charging/discharging rates.

\section{Minimum Control Step}

This characteristic is important, particularly during power management activities comprising local generation and demand. The managed asset have to provide a small difference in its output in response to a change in the supply/demand balance of a small scale system. On the other hand, there is a minimum control step limit for each DER, lower from which the set point differences do not cause any changes in device output. It can be observed by reducing the difference between two power set point adjustments until the device output is no longer changing.

\section{Maximum Response Delay}

Timing becomes crucial in regulation and contingency services requiring response ranging from seconds to a minute. Maximum response delay can simply be observed by measuring the time between when the maximum set point during standby operation is adjusted and when device output reaches to that level. For devices that are both capable of supplying and demanding power, the minimum duration required to change the output from maximum supply to maximum demand (or vice versa) must also be considered. In the field, for some inverters and DERs, it is a must to make transition from supply to demand or vice versa in two steps, by primarily adjusting power setpoint to 0 . Moreover, for some DERs amount of a new power setpoint step may be limited (for example maximum $10 \mathrm{~kW}$ adjustment steps, requiring 5 steps for reaching to the maximum power output of a $50 \mathrm{~kW}$ device), adding extra time to the maximum response delay.

\section{E. Standby Consumption}

The amount of power demanded during standby mode is of importance, especially for devices that are kept idle for long durations. It is the power output of a DER when zero is set as the power set point. Inverter losses and mechanical auxiliary are the main sources of standby consumption. For devices that do not get output feedback from the utility side of their connection point, steady state control errors are usually around standby power. In management activities for mitigating local network problems, devices with considerable amounts of standby consumption may even compensate the positive impact of other neighboring devices. For these reasons, it may be more suitable to keep them off, when they are not actively used at their high output levels, making their own consumption cost-effective.

\section{F. Comparative Strengths and Weaknesses}

Advantages and disadvantages of a DER compared to other DERs, can be verbally represented in this category. The content for this category do not only comprise management details that are not suitable for numerical description; but may also include a brief summary of other characteristics compared to other DERs. Details, such as resistance to overcharging/ overdischarging, storage capability, cycle life, shelf life and individual device specific details, such as time needed for mechanical start, comparative longitude of time that is needed to be waited before running a turned off DER again, additional control functions that available for use can be represented with simplicity at this section. Furthermore, costs and environmental impacts can even be compared. This content can be defined and further updated by device manufacturer/ retailer or even by user/customer through an interface.

\section{CASE STUdy with FIELD EXPERIMENTS}

Field experiments were conducted in a low voltage network with different types of DERs. The main purpose of the case study was to investigate effectiveness of and challenges in applying the management capability identification approaches in the field and to compare the characteristic differences and common features of different types of DERs. 
The system used in the tests was Distributed Energy Resources Test Facility of Ricerca sul Sistema Energetico (RSE DER-TF) [10-12]. The laboratory has a three phase LV (400V) AC distribution network, hosting different types of distributed generation (PV panel groups, small scale wind turbine, one-phase dispatchable CHP, three phase controllable CHP), storage devices (lead-acid battery group, lithium-ion battery group, vanadium redox battery) all with an overall capacity of $350 \mathrm{~kW}, 300 \mathrm{kVAr}$. The total storage capability of all the batteries is $230 \mathrm{kWh}$. The system is directly connected to a $23 \mathrm{kV}$ medium voltage (MV) grid through an $800 \mathrm{kVA}$ transformer. The network is flexibly configurable, providing connection availability for devices to different busses and adjustable line lengths. There is also a LV $(380 \mathrm{~V})$ DC microgrid with $\mathrm{NaNiCl}$ batteries and a bi-directional interface inverter.

All the tests were conducted using the host research infrastructure's SCAD custom software developed in LabVIEW. For monitoring, all the data collected by the measurement equipment as analog signals are converted into digital signals by DAQ cards and delivered to a central data server using various protocols. A human-machine interface (HMI) software, also developed in LabVIEW, connects to the SCADA and displays the real time data through a graphical user interface (Fig. 1). The HMI is also capable of starting and stopping the equipment, as well as defining power set points through this interface. Furthermore, the SCADA allows remote data exchange through various communication protocols.

\section{A. Characterization Tests}

During the tests, each DER was directly connected to the main bus of the network in parallel to each other except the $\mathrm{NaNiCl}$ battery group, which was serially connected to the DC microgrid converter (Figure 2). Identification methods were applied for several times to ensure the reliability of results.

Active/reactive power supply/demand capabilities of the tested DERs are provided in Table 1. It is notable that the maximum charging power of lead-acid battery group was limited to $5 \mathrm{~kW}$, while redox battery was not offering any reactive power control. On the other hand, DC microgrid converter only allowed reactive power management. When discharged with the maximum power rate, the lead-acid battery group and vanadium redox battery was able to last for an hour, while lithium-ion stood for 41 minutes and $\mathrm{NaNiCl}$ batteries held on for 28 minutes. The rated storage capacity of each battery group, when charged/discharged with rather lower rates $(5 \mathrm{~kW}$ for the lead-acid battery group, $9 \mathrm{~kW}$ for vanadium redox and $6 \mathrm{~kW}$ for lithium-ion and $\mathrm{NaNiCl}$ battery groups) is shown in Figure 3.

Minimum control step was found as $0.1 \mathrm{~kW}$ for the leadacid battery group, lithium-ion battery group, vanadium redox battery, $\mathrm{NaNiCl}$ battery group and $0.1 \mathrm{kVAr}$ for the DC microgrid converter. For the large CHP unit it was observed as $1 \mathrm{~kW}$. Since the small CHP unit was not controllable, its minimum control step was the same with its maximum output, $3.6 \mathrm{~kW}$. PV panel group had a number of locally and manually dispatchable subgroups and the minimum control step was equal to the output of the smallest subgroup. This minimum step was not constant and naturally dependent on the actual solar irradiation and temperature. The wind turbine was also locally and manually dispatchable without any additional steps and had variable output based on actual wind speed.

Maximum response delay was measured as 4 seconds for the lead-acid battery group, lithium-ion battery group, while it was 5 seconds for the $\mathrm{NaNiCl}$ battery group and DC microgrid converter. These values include monitoring and communication equipment delays that have impact on management activities. For the redox battery, the delay was up to 18 seconds. Moreover, during the first run of that asset, mechanical start took 4 minutes 30 seconds. The small CHP unit had a delay of 70 seconds and the large CHP unit had a response delay of 220 seconds in total. For locally and manually dispatchable PV panel group and wind turbine, the delay was based on local reaching time to the device by an individual (minutes) and analog switching (seconds).

DERs with standby consumption above $1 \mathrm{~kW}$ are shown in Figure 4. The tested DERs had advantages and drawbacks compared to each other. The lead-acid battery group charging power was limited to $5 \mathrm{~kW}$, while it could supply up to 20 $\mathrm{kW}$, limiting its management performance as a disadvantage compared to other batteries. The lithium-ion battery group had a longer cycle life compared to lead-acid and it was more suitable for frequent use. However it was the most overcharging and overdischarging sensitive asset in the system.

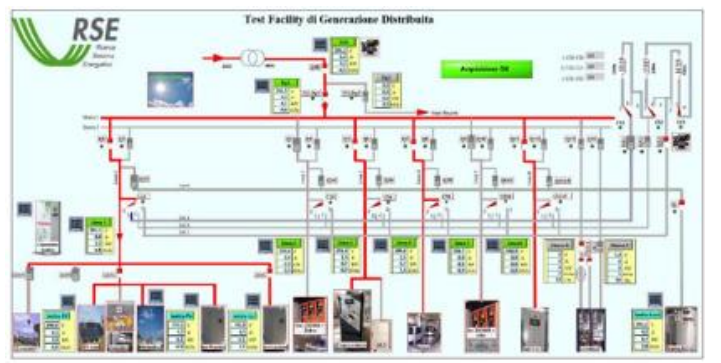

Fig. 1. Central monitoring and control interface of RSE DER-TF

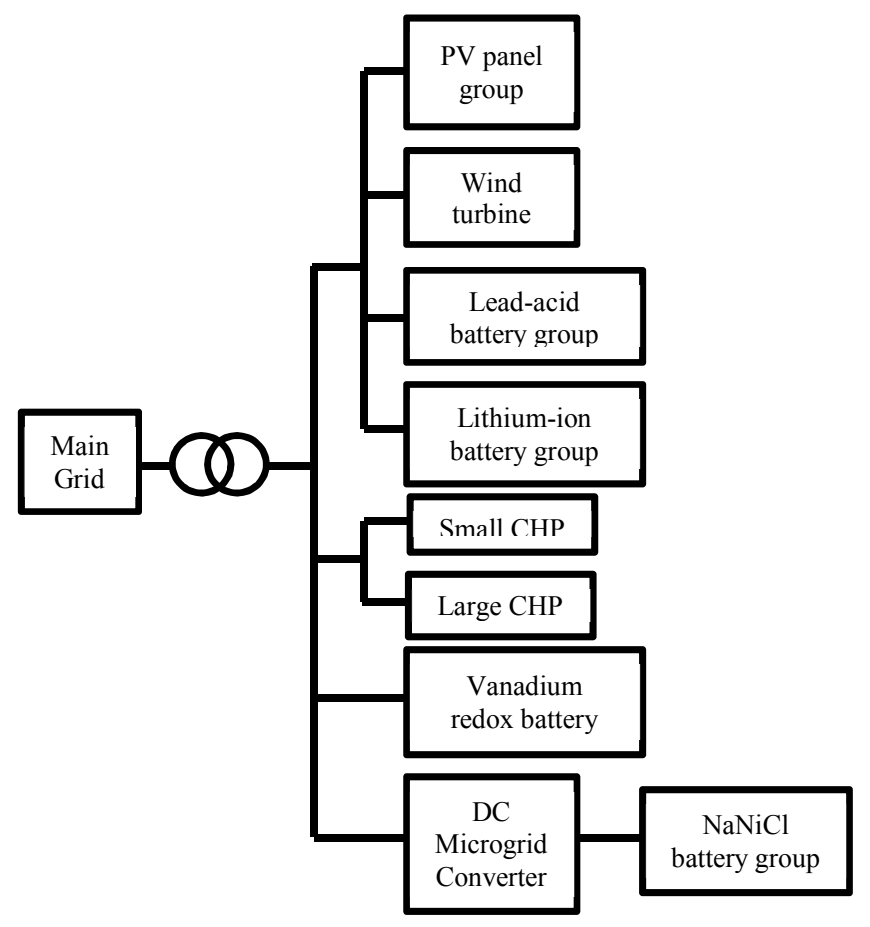

Fig. 2. The main setup for characterization tests 
The vanadium redox battery was the battery with the largest storage capacity; but without reactive power control capability. Moreover devices had important details that should be considered during management. For batteries, charging to discharging switching and vice versa should be done in two stages; at first output power is set to 0 , then set to a new value. This was done in order to prevent inverter failures. Similarly, the $\mathrm{NaNiCl}$ battery had a ramp limit of $10 \mathrm{~kW} / \mathrm{sec}$, while it was possible to manage the large CHP active power in 25 to $50 \mathrm{~kW}$ range. The vanadium redox battery was able to naturally cool down during operation cycle due to electrolyte transfer between its tanks. On the other hand, black start was a challenge since an auxiliary power source was needed for pumps during mechanical start. It also had high self-discharge around $1 \mathrm{~kW}$ due to cross conduction between positive and negative electrolyte tanks. $\mathrm{NaNiCl}$ batteries were temperature redundant, while extremely hot air should be transferred to open air space for cooling. Furthermore, because of high temperature regime, it took a very long time (tens of hours) to totally stop it and run again.

TABLE I. ACTIVE AND REACTIVE POWER SupPly AND DEMAND CAPABILITIES OF THE TESTED DERS

\begin{tabular}{|l|c|c|c|c|}
\hline \multirow{2}{*}{\begin{tabular}{l}
\multirow{1}{*}{$\begin{array}{c}\text { Device } \\
\text { Name }\end{array}$} \\
\cline { 2 - 5 }
\end{tabular}} & \multicolumn{2}{|c|}{$\begin{array}{c}\text { Active Power } \\
\text { [kW] }\end{array}$} & \multicolumn{2}{c|}{$\begin{array}{c}\text { Reactive Power } \\
\text { [kVAr] }\end{array}$} \\
\cline { 2 - 5 } $\begin{array}{l}\text { Lead-acid } \\
\text { Battery }\end{array}$ & 20.0 & 5.0 & 19.5 & 19.3 \\
\hline $\begin{array}{l}\text { Lithium-ion } \\
\text { battery }\end{array}$ & 32.0 & 32.0 & 32.0 & 29.0 \\
\hline $\begin{array}{l}\text { Vanadium } \\
\text { redox } \\
\text { battery }\end{array}$ & 30.0 & 45.0 & 2.0 & 2.0 \\
\hline Small CHP & 3.6 & 1.9 & 0 & $0.5-1.3$ \\
\hline Large CHP & 45 & 3 & 28 & $0.3-36$ \\
\hline $\begin{array}{l}\text { DC } \\
\text { Converter }\end{array}$ & 60 & 60 & 30 & 30 \\
\hline $\begin{array}{l}\text { NaNiCl } \\
\text { battery }\end{array}$ & 20.0 & 20.0 & - & - \\
\hline PV panel & 20 & - & 0 & 0 \\
\hline $\begin{array}{l}\text { Wind } \\
\text { turbine }\end{array}$ & 3 & - & 0 & 0 \\
\hline
\end{tabular}

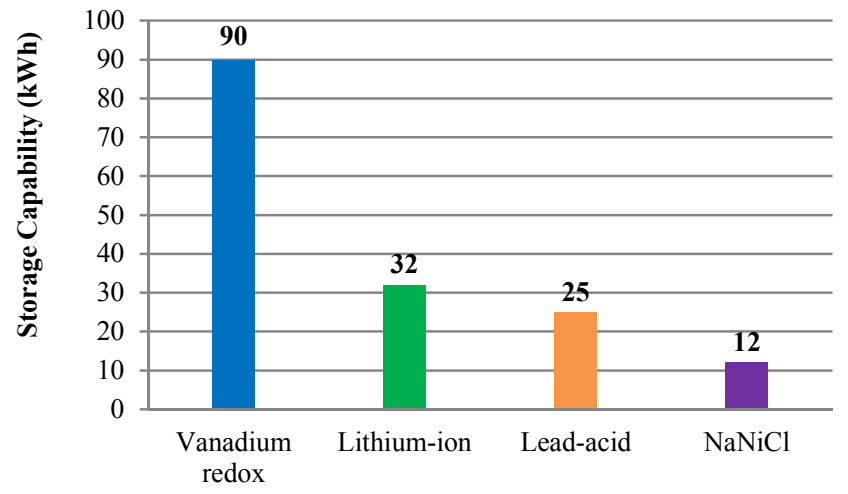

Fig. 3. Storage capability of each battery group

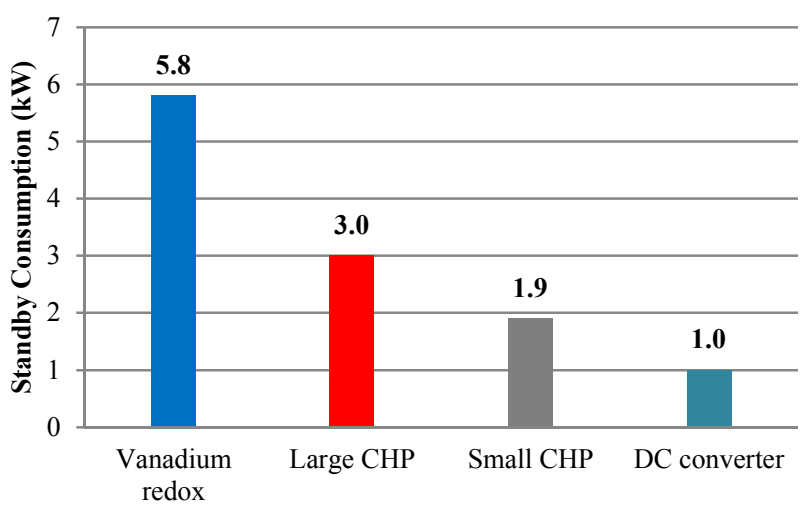

Fig. 4. DERs with standby consumption above $1 \mathrm{~kW}$

\section{B. PID Control Test}

Lead-acid battery group had an additional PID control mode that can be enabled. It got feedback from utility side of its inverter to get closer to adjusted setpoints. The impact of PID control on output accuracy was compared with of operation without PID. The results are provided in Table II. According to the results, PID control eliminated control errors except $20 \mathrm{~kW}$ discharging rate. On the other hand, it added 15 seconds more on response delay. For power management activities with short durations, PID may not offer considerable difference; while for energy management activities for hours, it can improve energy exchange accuracy up to $9 \%$.

\section{CONCLUSION}

This paper has proposed one of the first detailed field investigations of methods for identifying DER power and energy management capabilities. Many different types of DERs were tested and their performances were compared from several points of view. The identification methods highlighted the common and distinctive features of different types of DERs.

TABLE II. ACTIVE AND REACTIVE POWER SUPPLy AND DEMAND CAPABILITIES OF THE TESTED DERS

\begin{tabular}{|c|c|c|c|c|c|}
\hline \multirow[b]{2}{*}{ Mode } & \multirow{2}{*}{$\begin{array}{c}\text { Set } \\
\text { Value } \\
{[\mathrm{kW}]}\end{array}$} & \multicolumn{2}{|c|}{$\begin{array}{c}\text { Without PID } \\
\text { control }\end{array}$} & \multicolumn{2}{|c|}{ With PID control } \\
\hline & & $\begin{array}{c}\text { Power } \\
\text { Output } \\
{[\mathbf{k W ]}}\end{array}$ & $\begin{array}{c}\text { Error } \\
(\%)\end{array}$ & $\begin{array}{c}\text { Power } \\
\text { Output } \\
{[\mathrm{kW}]}\end{array}$ & $\begin{array}{c}\text { Error } \\
(\%)\end{array}$ \\
\hline \multirow{7}{*}{ Discharging } & 5.00 & 5.24 & 4.58 & 5.00 & 0.00 \\
\hline & 5.50 & 5.74 & 4.18 & 5.50 & 0.00 \\
\hline & 10.00 & 10.60 & 5.66 & 10.00 & 0.00 \\
\hline & 10.50 & 11.10 & 5.41 & 10.50 & 0.00 \\
\hline & 15.00 & 15.91 & 5.72 & 15.00 & 0.00 \\
\hline & 15.50 & 16.40 & 5.49 & 15.50 & 0.00 \\
\hline & 20.00 & 19.40 & 3.09 & 19.50 & 2.56 \\
\hline \multirow{2}{*}{ Charging } & -2.50 & -2.7 & 7.41 & -2.50 & 0.00 \\
\hline & -5.00 & -5.5 & 9.09 & -5.00 & 0.00 \\
\hline
\end{tabular}


The tested batteries without mechanical parts (all except vanadium redox) had small control steps, fast response and negligible standby consumption. On the other hand, their longest service duration with maximum power output is an hour. Therefore, they are quite suitable for grid services like regulation and contingency.

Devices with electromechanical parts have rather longer response delays compared to the others. Therefore, they are not suitable for the events requiring fast responses that are smaller than a minute. The tested CHP units and vanadium redox battery had also high standby consumption. This kind of devices should not be operated at zero or low power setpoints and should be used at events requiring high and cost-effective power output levels. DC microgrid converter had similar management capability with the batteries from the point of response speed, since they didn't comprise mechanical parts which are the reasons of response delays. However it had higher standby consumption and it only provided reactive power control. Therefore microgrid converter is classified into the middle range among other DERs, from the point of overall management capability. DERs without remote control and communication options, such as the tested PV panel group and wind turbine, can only be dispatched by field crews/prosumers constraining their involvement in aggregated and dynamic events. In energy management activities, battery charge/discharge rates can be adjusted to lower levels than maximum points for the sake of utilizing rather higher percentage of the maximum storage capacity.

In field experiments, the devices were mainly tried to be characterized due to their classes and types. However many device-specific and field-specific characteristic limits were observed. Therefore, in addition to device type and classbased characterization approaches, individual device and field specific functions need to be known and briefly presented to device users in a standardized way. An open issue is the existence of nonlinear differences between the set values and the actual responses of devices. Even they are low in percentage, they may lead to considerable unintended results in long term energy management applications. This issue is due to device and inverter nature and may vary from device to device. Moreover, new control approaches that are integrated to existing inverters may change error ratings. Additional control approaches like PID seems to be a must especially for energy management activities.

The future work is intended to be on adoption of gamification techniques for motivating the distributed generation and storage system owners, towards effective power and energy management activities. It will be done by brief and clear representation of current and near future state of system parameters to the operators and by creating suggestions for effective management actions according to event and system conditions. Continuous performance improvement through short and long term performance evaluation will also be explored in these studies. Another focus for future works will be integration of innovative tariff structures developed for demand response applications, into DER management activities [13].

\section{ACKNOWLEDGEMENT}

This research has been performed using the ERIGrid Research Infrastructure and is part of a project that has received funding from the European Union's Horizon 2020 Research and Innovation Programme under the Grant Agreement No. 654113. The support of the European Research Infrastructure ERIGrid and its partner RSE S.p.A. is very much appreciated.

The authors wish to acknowledge financial support provided under the framework of ERA-Net Smart Grids Plus by "The Scientific and Technological Research Council of Turkey (TUBITAK)" from Turkey and "The Foundation of Science and Technology (FCT)" from Portugal.

\section{REFERENCES}

[1] Stem (2017, September). Grid services with Stem. [Online]. Available: http://www.stem.com/grid/

[2] R. Hara, H. Kita, T. Tanabe, H. Sugihara, A. Kuwayama, S. Miwa. "Testing the technologies," IEEE Power and Energy Magazine, vol. 7, issue 3, pp. 77-85, May 2009.

[3] X. Liu, A. Aichhorn, L. Liu, H. Li. "Coordinated control of a distributed energy storage system with tap changer transformers for voltage rise mitigation under high photovoltaic penetration," IEEE Transactions on Smart Grid, vol. 3, issue 2, pp. 897-906, February 2012.

[4] D. Stimoniaris, D. Tsiamitros, E. Dialynas. "Improved energy storage management and $\mathrm{PV}$-active control infrastructure and strategies for microgrids," IEEE Transactions on Power System, vol. 31, issue 1, pp. 813-820, January 2015.

[5] Electric Power Research Institute (EPRI) (2016, December). Common Functions for Smart Inverters. [Online]. Available: http://www2.epri.com/abstracts/Pages/ProductAbstract.aspx? ProductId $=000000003002008217$

[6] R. Hledik, J. Lazar, L. Schwartz (2016, May). Distribution System Pricing with Distributed Energy Resources. [Online]. Available: https://emp.lbl.gov/sites/default/files/feur_4_20160 518_fin-links2.pdf

[7] Electric Power Research Institute (EPRI) (2016, November). Common Functions for DER Group Management. [Online]. Available: https://www.epri.com/\#/pages/product/00000000300 2008215/

[8] D. J. Olsen, N. Matson, M. D. Sohn, C. Rose, J. Dudley, S Goli et. al. (2013, September). Grid Integration of Aggregated Demand Response, Part I: Load Availability Profiles and Constraints for the Western Interconnection. [Online]. Available: https://energy.gov/eere/analysis/downloads/gridintegration-aggregated-demand-response-part-1-load-availability

[9] P. Cappers, J. MacDonald, J. Page, J. Potter, E. Stewart (2016, January). Future Opportunities and Challenges with Using Demand Response as a Resource in Distribution System Operation and Planning Activities. [Online]. Available: https://emp.lbl.gov/sites/all/files/lbnl-1003951.pdf

[10] Ricerca sul Sistema Energetico (RSE) S.p.A. (2017). Low voltage distributed energy resources test facility. [Online]. Available: http://www.rse-web.it/laboratori/laboratorio/32

[11] C. Sandroni, M. Verga, R. Lazzari, M. Fantini, M. Sacchi and V. Prandoni, "RSE's microgrid: A facility for research, development and testing of future distributed generation and microgrid technologies," in AEIT International Annual Conference (AEIT) 2016, pp. 1-6.

[12] D. Ronchegalli and R. Lazzari, "Development of the control strategy for a direct current microgrid: A case study," in $A E I T$ International Annual Conference (AEIT) 2016, pp. 1-6.

[13] M. A. Zehir, M. H. Wevers, A. Batman, M. Bagriyanik, J. L. Hurink, U. Kucuk et. al., "A Novel Incentive-based Retail Demand Response Program for Collaborative Participation of Small Customers," in IEEE PowerTech 2017, pp. 1-6. 